\title{
Who Plays the Numbers Games in the Middle of the Day?
}

\author{
Kathryn L. Combs \\ John A. Spry \\ Department of Finance \\ University of St. Thomas \\ klcombs@stthomas.edu \\ jaspry@stthomas.edu
}

June 2007

\begin{abstract}
We analyze the increase in sales of daily numbers lottery games - Pick 3 and Pick 4 games - after Ohio introduced midday drawings in August 1999. Using a 36 month panel data set of Ohio lottery sales by zip code we find that midday drawings increased Pick 3 sales by $12.1 \%$ per adult and increased Pick 4 sales by $16.6 \%$ per adult. The increase in both Pick 3 and Pick 4 sales after midday drawings began was greater in zip codes with a greater percentage of households receiving public assistance and zip codes with a higher percentage of black residents. The Pick 3 Red Ball promotions during this period, which increased the payouts to winning Pick 3 tickets, were successful in raising Ohio Lottery sales and profits. Pick 3 sales per adult would have declined $15.4 \%$ and Pick 4 sales per adult would have dropped 2.4\% between 1998 and 2000 without any marketing innovations by the Ohio Lottery. This trend of falling lottery sales over time was more severe in areas near casinos, many of which opened in the mid 1990s.
\end{abstract}




\section{Introduction}

State lotteries are a significant source of both revenue and controversy. The 42 state lotteries, along with the District of Columbia lottery and the Puerto Rico lottery, generated $\$ 17$ billion in profits from the sale of $\$ 57$ billion of lottery games in fiscal year 2006. ${ }^{1}$ This thirty percent average profit margin for lotteries is used to fund public expenditures. Lottery critics argue that state lottery tickets are disproportionately purchased by disadvantaged individuals.

Clotfelter and Cook (1987) label the total losses from lottery players less administrative and transactional costs the "implicit lottery tax" given the state grants itself the exclusive legal right to sell lottery games. A common critique of lotteries is that the burden of the implicit lottery tax disproportionately falls on those with the lowest ability to pay. A large empirical literature overwhelmingly finds that state lotteries as a whole are a regressive source of revenue. ${ }^{2}$

A more recent branch of lottery research has discovered that not all lottery products are equally regressive. Studies that have examined the tax burden of different lottery products have generally found that games offering larger jackpots and longer odds are less regressive than lottery games offering smaller prizes. Hansen (1995) finds that Colorado instant games are regressive. Price and Novak (1999 and 2000) find that the Texas Lotto, which offers jackpots over a million dollars, is less regressive than the Texas Pick 3 or instant games in Texas. Spry (2003) examines Indiana lottery sales using

\footnotetext{
${ }^{1}$ North American Association of State and Provincial Lotteries. http://www.naspl.org/index.cfm?fuseaction=content\&PageID=3\&PageCategory=3

2 See, for example, Clotfelter and Cook (1979, 1990), Cornwell and Mustard (2001), Garrett and Marsh (2002), Hansen (1995), Hansen et al. (2000), Price and Novak (1999, 2000), Scott and Garen (1994), Spiro (1974), Spry (2003), and Tosun and Skidmore (2004).
} 
zip code data from 1995 to 2000. Instant scratch games are the most regressive Indiana lottery product. Pick 3 and Pick 4 daily number games are slightly less regressive than scratch games in Indiana. Hoosier Lotto and Powerball in Indiana both have income elasticities of demand of approximately 0.9 . This reflects the slightly regressive nature of Hoosier Lotto and Powerball in Indiana. The multi-state Powerball offers jackpots of tens of million dollars and occasionally jackpots grow to hundreds of millions dollars. Oster (2004) finds that on average Powerball in Connecticut is a regressive form of taxation. However, in response to large jackpots, higher income consumers increase their purchases of Powerball more than lower income consumers. Oster shows this leads to the possibility of Powerball being a progressive source of government revenue for very large jackpots.

Lottery officials face a trade-off between mitigating the regressiveness of the lottery as a source of revenue and maximizing lottery profits. The above results suggest that lottery marketers could engineer a less regressive state lottery by adjusting the product mix toward large jackpot games. Alternatively, lottery marketers could focus on developing new games to maximize lottery revenue. This tradeoff may become increasingly challenging due to lottery fatigue as a lottery matures. Many American lotteries have had difficulty maintaining the same level of excitement over time with the same lottery products and jackpots, as players become bored with "the same old game."

After the election of a new governor in 1998, the Ohio Lottery launched new lottery products to "increase revenues through product research, design, development, and support.”3 In an attempt to reverse declining sales, the Ohio Lottery launched midday drawings for the Pick 3 and Pick 4 games on August 16, 1999. Many states have

\footnotetext{
${ }^{3}$ http://www.ohiolottery.com/about/about_us.html
} 
introduced midday lottery drawings in an effort to boost lottery sales and state lottery profits. Twenty-three lotteries offer midday Pick 3 drawings. ${ }^{4}$ Twenty-one lotteries offer midday Pick 4 drawings. ${ }^{5}$ The Ohio Lottery also ran Red Ball promotions for the Pick 3 game featuring better odds for players in June and July 1999 and April and May 2000.

This paper uses a panel of monthly lottery sales and socioeconomic variables for 1004 zip codes from January 1998 to December 2000 to examine the changes in sales of the Pick 3 game per adult and the Pick 4 game per adult. We first examine the effectiveness of the Red Ball Pick 3 promotion in increasing the volume of Pick 3 sales, total revenue from the Pick 3 game, and Ohio lottery profits. Second, we estimate the gain in Ohio Lottery sales and profits caused by the introduction of midday drawings. Finally, the rich panel data lets us control for individual, time-invariant zip code fixed effects to test whether the change in sales of Pick 3 and Pick 4 games caused by the introduction of midday drawings is uniform across the state or stronger in zip codes with specific socioeconomic characteristics.

\section{An Introduction to the Ohio Lottery}

Ohio is one of 42 states with a state lottery. The Ohio Lottery transfers 100 percent of its profits, $\$ 646.3$ on $\$ 2.22$ billion in sales in fiscal year 2006 , to education. ${ }^{6}$ The Ohio lottery has struggled to maintain sales in the face of lottery fatigue and increasing

\footnotetext{
${ }^{4}$ Other lotteries offering midday pick 3 drawings include California, Connecticut, Delaware, Georgia, Illinois, Iowa, Indiana, Kentucky, Maine, Maryland, Michigan,, Missouri, New Hampshire, New Jersey, New York, Pennsylvania, South Carolina, Tennessee, Texas, Vermont, Virginia, and Washington, D.C. Source: http://www.betslips.com/orderp3.aspx?partner=101

${ }^{5}$ Other lotteries offering midday pick 4 drawings include Connecticut, Delaware, Georgia, Illinois, Iowa, Indiana, Kentucky, Maine, Maryland, Michigan, Missouri, New Hampshire, New Jersey, New York, Pennsylvania, South Carolina, Tennessee, Vermont, Virginia, and Washington, D.C. Source: http://www.betslips.com/orderp4.aspx?partner=101 ${ }^{6}$ http://www.ohiolottery.com/pdf/2006_CAFR.pdf
} 
competition from casinos in Indiana, Michigan, and West Virginia. When introducing midday drawings for the Pick 3 and Pick 4 games in 1999, Ohio Lottery Commission Chairman Sandra K. Barber said, "We're a mature lottery, and we have to continue to come up with new ideas." ${ }^{7}$ Table 1 shows that total Ohio Lottery sales peaked at \$2.31 billion in 1996.

Ohio's lottery products have a large realized (ex-post) average loss for consumers of lottery tickets. This loss is the state's gain. The state's profits are the total losses from lottery players less administrative costs and payments to retailers, and thus become the “implicit lottery tax.” The state of Ohio transferred \$646 million in profits towards education funding in fiscal year 2006, down from a peak profit transferred to education of $\$ 749$ million in fiscal year $1997 .^{8}$

The Ohio Lottery offers a variety of lottery products as shown in Table 1. Included in the array of products are so-called numbers games, Pick 3 games and Pick 4 games. Pick 3 games offer players the opportunity to choose three numbers. If players pick all three numbers in order, a one dollar straight bet, they win $\$ 500$. This standard Pick 3 bet has 1 in 1000 odds, so this Pick 3 bet has an expected return of fifty cents for every dollar bet. There are also a variety of boxed bets in which a player wins if the three numbers from the drawing match the player's numbers in any order. There are also a pair, back-up, and wheel bets in the Pick 3 game. Each of these Pick 3 bets has an expected return of fifty cents on a dollar bet. This expected return is quite low compared to bets in casino games.

\footnotetext{
${ }^{7}$ Cleveland Plain Dealer. "Lottery to Launch Lunch Games; Commission Decides to Add a Second Daily Pick 3 and Pick 4 Drawing in an Attempt to Reverse Decline in State Gambling Revenues.” July 15, 1999. ${ }^{8}$ http://www.ohiolottery.com/pdf/2006_CAFR.pdf
} 
Pick 4 games offer players the opportunity to choose four numbers. If a player picks all four numbers in order, a one dollar straight bet, they win $\$ 5,000 .^{9}$ This standard straight Pick 5 bet has 1 in 10,000 odds. The Pick 4 straight bet also has an expected return of fifty cents for every dollar bet. The longer odds in Pick 4 create larger maximum prizes than in the Pick 3 game. The Pick 4 game also has back-up and wheel bets. The expected return on each Pick 4 bet is also quite low compared to bets in casinos. The Ohio Lottery pays approximately 6.28\% of Pick 3 and Pick 4 sales to lottery retailers as commission and bonuses for selling winning lottery tickets. ${ }^{10}$

The numbers games have a colorful history in Ohio. Before the creation of the Ohio Lottery in 1973, colorful characters such as Don King and Virgil Ogletree ${ }^{11}$ ran number games or "policy racket” games in Cleveland. These illegal numbers games were very similar to the Ohio Lottery’s Pick 3 and Pick 4 number except for their higher payouts and their profits accruing to the illegal operators of the numbers games instead of the state. These illegal games were based on random numbers that appeared in newspapers, such as the last digits of stock and bond volumes.

"At his height, he (Virgil Ogletree) was one of a handful of Cleveland powers in the numbers games, the black-market predecessor to the Ohio Lottery. Typically taking in $\$ 20,000$ in bets daily with 40 to 50 runners working for him, he was friendly with fellow numbers magnate and later boxing promoter Don King. 'Don King and the others, they had business,' said Ogletree's longtime lawyer and friend James Willis, who often represented the other major players, too. "But I don't think it was as large

\footnotetext{
${ }^{9}$ Perhaps the most famous straight Pick 4 Bet in Ohio Lottery History occurred when the Pick 4 evening drawing had the result of 4-2-3-9 shortly after Ohio State defeated Michigan in football in 2006 by the score of 42 to 39 . Over $\$ 2.2$ million in Pick 4 prizes were paid by the Ohio Lottery on those numbers. ${ }^{10}$ Email from Mardele Cohen, Ohio Lottery Communications. November 27, 2006.

${ }^{11}$ A colorful character projecting wealth and deep pockets was important to earn the trust of bettors. Ogletree famously drove a customized Cadillac. Ogletree was quoted in the Cleveland Plain Dealer saying, "In the numbers business, you have to drive a fancy car. It is necessary to have an impressive image. People will not go to a shabby numbers bank."
} 
as his. Virgil Ogletree made as much money, if not more money, booking the numbers than anybody ever did in the state of Ohio."12

The director of the Iowa lottery writes, “In certain instances where 'daily numbers' games are sold in large metropolitan areas from St. Louis east, there exists a cultural anomaly where lower-income blue-collar workers play the game in distinctly higher proportions that their white-collar counterparts. Data will show that this particular game has a lower-income following. The game was sold by organized crime for generations. Government lotteries in Washington D.C., Boston, Baltimore, New York, and elsewhere took almost all of that business away from organized crime. Proving that this phenomenon is a cultural rather than an economic bias is the fact that the same game, sold by lotteries to the same economic demographic west of St. Louis, has resulted in relative consumer rejection and virtual failure. Cities west of St. Louis developed into urban areas later and were devoid of the criminal numbers running tradition. The game is a cultural preference.”13

Pick 3 sales in Ohio peaked in 1996 at \$450.6 million. Table 1 and Figure 1 show that Pick 3 sales rebounded in fiscal 2000 (July 1999 to June 2000) after the Pick 3 midday drawings began in August 1999. However, sales of the Pick 3 game have continued to decline in recent years. Table 2 shows Pick 3 and Pick 4 sales as a percentage of total Ohio Lottery sales. Pick 3 was a declining share of lottery sales before the midday drawings began in August 1999. There was a slight rebound in Pick 3

\footnotetext{
${ }^{12}$ Cleveland Plain Dealer. "King of Cleveland Numbers Racket Dead: Virgil Ogletree, 84, Made, Lost a Fortune.” January 25, 2007.

${ }^{13}$ Edward J. Stanek. "A Critique of Lottery Critics" President of the North American Association of State and Provincial Lotteries. September 29, 1997. Online at http://www.nmlottery.com/Miscellaneous/CRITIQUE.HTM
} 
sales as a percentage of total sales after the midday drawings began, but then Pick 3 continued to decline as a share of all lottery sales.

The Pick 4 games have trailed Pick 3 games in sales volume. After stagnant sales from fiscal year 1998 to 1999, Pick 4 sales increased by $\$ 27.9$ million in fiscal year 2000 after the introduction of Pick 4 midday drawings in 1999. In contrast to the Pick 3 game, Pick 4 sales have steadily grown in recent years. In 2006, the Ohio Pick 4 games recorded record sales of $\$ 175.7$ million. Pick 4 sales as a share of total lottery sales have increased over time. Pick 4 sales jumped from 5.8\% of total Ohio Lottery sales in fiscal year 1999 to $7.8 \%$ of total sales in fiscal year 2001, the second fiscal year with midday drawings for the Pick 4 game.

On Aug. 16, 1999 Ohio launched midday drawings for Pick 3 and Pick 4 number games. The midday drawing, held at 12:29 p.m., is an addition to the traditional 7:29 p.m. drawing. By adding the midday drawing, the lottery doubled the number of weekly drawings from six to twelve. The Ohio Lottery did not hold Sunday drawings until May 20, 2007. The midday drawings permit players to place bets for the Pick 3 and Pick 4 games anytime after 7:30 pm and receive the resolution of the bet by 12:29 pm instead of waiting until 7:29 pm the following day. This more exciting and rapid play could be viewed as an attempt to compete with the instant excitement and resolution of a bet associated with casino gambling. Midday drawings also allow lottery players to play twice a day instead of just once a day. Players can actually place a bet on a drawing several days in advance. However, if gamblers crave or seek excitement, having more opportunities to place a bet may offer more opportunities for excitement. 
Midday drawings for Pick 3 and Pick 4 games have been criticized as targeting vulnerable individuals. Gambling opponent The Rev. Tom Grey said, “The only thing convenient about having more daily lottery drawings is that it makes it more convenient for government to sucker more people out of more money." ${ }^{14}$ The Cleveland Plain Dealer reported in 1999, “The Ohio Lottery's decision to increase its take by adding midday drawings could be a tremendous detriment to Cleveland neighborhoods, (Cleveland) City Council members decided last night in throwing unanimous support to a measure opposing the new games of chance. Councilman Joe Cimperman said second daily drawings in the Pick 3 and Pick 4 games affected Cleveland's poorest sections the most, pinching the wallets of families who could better spend the money on food, clothing and housing. 'It inevitably impacts poor neighborhoods more than neighborhoods of affluence,' said Cimperman, who sponsored a council resolution urging the state to reconsider the new drawings. 'It's not an equal opportunity taker.' Lottery officials, who could not be reached last night, said earlier they doubled the drawings to boost slipping sales and had no strategy or intention to target the poor or blacks.”15

In another effort to boost sagging Pick 3 sales, the Ohio Lottery ran Red Ball promotions in June and July 1999 and April and May 2000. The Red Ball promotion increases the payouts to winning tickets in the Pick 3 game about approximately twenty percent when a red ball is drawn from a tumbler. When a red ball is drawn, then a straight Pick 3 bet pays $\$ 599$ instead of $\$ 500 .{ }^{16}$ The goal of the Red Ball promotion is to

\footnotetext{
${ }^{14}$ August 4, 1999. Cincinnati Post “Ohio Lottery Adds Midday Drawings”

15 "Lottery Expansion Opposed by Council; Games Target Poor, Cimperman Says" The Cleveland Plain Dealer. October 19, 1999. Page B1.

${ }^{16}$ Lottery prizes under $\$ 600$ do not have to be reported to the IRS by the Ohio Lottery.
} 
increase the volume of Pick 3 bets by enough to increase total revenue and profits from the Pick 3 despite the better odds for players.

During the first Red Ball promotion in June and July 1999, there were initially ten balls (nine white balls and one red ball) in the separate tumbler. When a white ball was drawn it was removed from the tumbler for the next Red Ball drawing. After a Red Ball was drawn all ten balls were reloaded into the tumbler. A Red Ball was expected to be drawn about once in every 5.5 drawings. This Red Ball promotion changes the expected payout of a dollar bet from 50 cents to between 50.99 cents and 59.99 cents depending on number of balls in the tumbler based on recent Red Ball drawings. On average the expected payoff is 51.8 cents.

The second Red Ball promotion in April and May 2000 was set up like the first except that initially only seven balls (six white balls and one red ball) were placed in the separate tumbler. With this modification in the odds, a Red Ball was expected to be drawn about once in every 4 drawings. This Red Ball promotion changes the expected payout of a dollar bet from 50 cents to between 51.41 cents and 59.99 cents depending on number of balls in the tumbler based on recent Red Ball drawings. On average the expected payoff is 52.48 cents.

\section{Data}

We construct a rich panel of Ohio lottery data, socioeconomic variables, and proximity to casinos. The Ohio Lottery provided 36 months of Ohio Lottery sales data for 1004 residential zip codes from January 1998 through December 2000, for a total of over 36,000 zip-code-month observations. The Ohio Lottery also provided data about the size of the Ohio Super Lotto weekly jackpots for the 36 month time period. A cross 
section of socioeconomic data for each residential zip code, from the Sourcebook of Zip Code Demographics 1999 and the U.S. Census 2000, includes measures of income, population, ethnicity, age, education, and percentage of households on public assistance. The distance from each zip code to the nearest casino was calculated using the software included with the Sourcebook of Zip Code Demographics 1999.

We use only residential zip codes in our analysis because we should not attribute sales in a non-residential zip code, such as an airport or major employer, to the few individuals that are reported to be residing in a non-residential zip code. We converted the monthly sales data to sales per day to account for uneven accounting periods in the monthly data provided by the Ohio Lottery. Adult population data by zip code from Sourcebook of Zip Code Demographics 1999 was used to compute the dependent variables, sales per day per adult for Pick 3 games and sales per day per adult for Pick 4 games.

In order to investigate the effect of the midday drawing and other lottery-related events and characteristics on Pick 3 and Pick 4 sales, we created additional variables. First, we created a dummy variable for entire months with the midday drawing, which was introduced on August 16, 1999. The midday drawing dummy variable equals 1 starting with the first full month in which the midday drawing was in effect (September 1999), and is equal to 0 prior to this time. For August 1999, we created a separate dummy variable that is 1 during this introductory month, and is equal to 0 for all other months.

Second, we created a dummy variable for the Pick 3 Red Ball promotion, which increased the expected value of Pick 3 winnings by increasing payouts when a Red Ball 
was drawn. This promotion ran on two occasions, for two months each, during our time period. The Red Ball promotion dummy variable equals 1 when the Red Ball promotion was in effect (June and July 1999 and April and May 2000) and zero if not. Finally, a variable related to the Super Lotto jackpot was created, since high jackpots could potentially affect sales of the Pick 3 or Pick 4 numbers games, either attracting participation in the lottery overall or providing a substitute to the numbers games. Using data on weekly Super Lotto jackpots provided by the Ohio Lottery, we calculated the monthly average jackpot size, whose mean is approximately $\$ 11.6$ million, with a minimum of $\$ 6.1$ million and a maximum of $\$ 26.3$ million.

\section{Descriptive Statistics}

Table 3 reports descriptive statistics for each variable. Pick 3 sales, the more popular of the two numbers games, has average sales of about 9 cents per day per adult, or about \$33 per year per adult for the average zip code. Some zip codes had no Pick 3 sales. The highest Pick 3 sales were about $\$ 2.60$ per day per adult (\$949 per year per adult). Pick 4 sales averaged about 3 cents per day per adult (about \$11 per year per adult for the average zip code) with a zero minimum and about an 80-cent maximum (\$294 per year per adult).

The socioeconomic variables used in this paper include measures of income, race, age, education, and households on public assistance. Per capita income in 1999 averaged $\$ 17,099$ across zip codes. The percent of population that was black for 1999 averaged approximately $7 \%$ across zip codes, with a minimum of $0 \%$ and a maximum of about 98\%. The percent of the population aged 65-99 for 1999 averaged about $12 \%$ with a minimum of $0 \%$ and maximum of $100 \%$. The percent of households on public assistance 
averaged about $3 \%$ with a minimum of $0 \%$ and a maximum of about $32 \%$. The percent of adults over 25 having a college degree or greater education averaged about $16 \%$ across zip codes with a minimum of $0 \%$ and a maximum of about $91 \%$.

Part of the impetus of the midday drawing is to improve the attractiveness of the Ohio Lottery’s Pick 3 and Pick 4 games with respect to the casinos. One attractive feature of casino gambling is the excitement of a quick resolution to the bet. Some of Ohio's lottery products, such as Super Lotto, have twice-a-week drawings that provide far from a quick resolution. The Pick 3 and Pick 4 games provide a quicker resolution of the bet with daily drawings, becoming even more exciting with the twice-daily drawing innovation of August 1999. Nonetheless, casino gambling is a potential substitute for Pick 3 and Pick 4 lottery games. To capture the effects of casino proximity on Pick 3 and Pick 4 sales, we computed the distance from each zip code to the nearest of the six casinos that were operating in bordering states. Ohioans on average are located about 67 miles from the nearest casino, with a minimum trip of 2 miles (near Wheeling, West Virginia) and no further than 127 miles from the nearest casino.

\section{The Effects of Midday Drawings and the Red Ball Promotion on Lottery Sales}

The sales of numbers games show seasonal variation and other variation over time. Figure 2 shows a plot of monthly sales per day per adult of Pick 3 and Pick 4 games (averaged across zip codes) from January 1998 through December 2000. Sales trend downward for both series for at least the first six months, with a subsequent upward trend. Ultimately sales in the last six months of the sample period are well above the earlier lows. Whether this apparent rise in sales is attributable to the midday drawing 
introduction in mid-August 1999 will be examined using regression so that we can control for seasonality, the Red Ball promotion, and other factors that affect lottery sales.

We first estimate the following regression model for Pick 3 sales per day per adult and also for Pick 4 sales per day per adult:

$$
y_{i t}=x_{i t}^{\prime} B+z_{i}^{\prime} \alpha_{i}+e_{i t}
$$

where i indexes zip codes and t indexes months. This specification includes 11 monthly dummy variables to control for seasonality in the demand for number games. January is the omitted month. The model includes a time trend variable ( $\mathrm{t}=1$, 2 , etc) to control for trends in Pick 3 and Pick 4 sales. The Red Ball dummy variable measures the effects of the Red Ball promotion. The Midday Introductory Month dummy variable measures the effect of a partial month of midday drawings in August 1999. The full month Midday drawing measures the effects of the midday drawings during an entire month beginning in September 1999. A constant term is included. Finally, cross-sectional fixed effects control for heterogeneity across zip codes.

Table 4 reports the regression results. The regression for Pick 3 sales per day per adult explains a great deal of the variation in sales with an R-squared of .981. The time trend coefficient is -0.00039 and is highly statistically significant. This means that over the 36 months in our sample, Pick 3 sales per day per adult for the average zip code would decline $\$ 0.014$ or $15.4 \%$ without any policy innovation by the Ohio Lottery. This is consistent with aggregate data showing the declining Pick 3 sales that motivated the Ohio Lottery to try midday drawings in the first place.

Pick 3 sales increase about $\$ 0.011$ per day per adult following the introduction of midday drawings. This is an estimated $12.1 \%$ increase in Pick 3 sales due to the midday 
drawing. This is highly statistically significant with a t-statistic of 20.19. Sales increased slightly less, \$0.008 per day per adult (8.9\%) in August 1999, the introductory month for midday drawings.

The Red Ball promotion increases Pick 3 sales per day per adult by $\$ 0.00458$, or $5.1 \%$. On average the Red Ball promotions increase the expected payout to players from $50 \%$ to $52.14 \%$. This is a $4.28 \%$ increase in payouts to players. The price of buying a dollar worth of expected Pick 3 game winnings falls from $\$ 2.00$ to $\$ 1.9179$ during the Red Ball promotion. This is a 4.105\% decrease in the price of playing Pick 3 during the Red Ball promotion. Therefore the estimate own-price elasticity of demand for Pick 3 is -1.24. We are somewhat cautious about this estimate since we observe only monthly data and the rules of the Red Ball promotion result in the odds of the game fluctuating from drawing to drawing.

The estimated response of players to the Red Ball promotion can be used to estimate the resulting effect on the Ohio Lottery's Pick 3 profits. The Ohio Lottery pays 6.28\% of total sales to retailers for their services selling the games to lottery players. Therefore we estimate Pick 3 sales net of payments to retailers increased 4.78\%. Since the increase in volume is a bit larger than the increase in payouts to players the Red Ball promotion does increase Ohio Lottery profits from the Pick 3 game.

Figure 3 shows a graph of predicted Pick 3 sales per day per adult for an average zip code. The diamonds show predicted Pick 3 sales per day per adult using the entire regression model from Table 4. This curve and the monthly dummy variables show that seasonality has important effects on the sales of the Pick 3 game. Pick 3 is less popular towards the middle of the year. The curve with squares shows predicted Pick 3 sales with 
the seasonal effects removed. This curve shows the strong negative time trend, two temporary jumps in Pick 3 sales due to the Red Ball promotion in June and July 1999 and April and May 2000, and the large gain in sales due to the midday drawings beginning on August 16, 1999.

The regression results for Pick 4 games per day per adult are reported in Table 4 and Figure 2. The regression for Pick 4 sales per day per adult explains a great deal of the variation in sales with an R-squared of .968. In contrast to the Pick 3 game, the time trend coefficient is only -0.00002 . It is statistically different from zero. This means that over the 36 months in our sample the average zip code Pick 4 sales per day per adult would decline only $\$ 0.00072$ or $2.4 \%$ without any policy innovation by the Ohio Lottery.

Pick 4 sales increase about $\$ 0.00498$ per day per adult following the introduction of midday drawings. This is an estimated $16.6 \%$ increase in Pick 4 sales due to the midday drawing. This is highly statistically significant with a t-statistic of 22.51. Pick 4 sales increased slightly less, \$0.00227 per day per adult (7.6\%) in August 1999, the introductory month for midday drawings.

Interestingly, we find evidence that the Pick 3 game is a complement to the Pick 4 game. When the price of playing the Pick 3 game falls $4.105 \%$ during the Red Ball promotion, there is a small increase in Pick 4 sales per day per adult of $\$ 0.00066$ or $2.2 \%$. Therefore, the cross-price elasticity of demand for Pick 4 with respect to the price of Pick 3 is -.54 .

Figure 4 shows a graph of predicted Pick 4 sales per day per adult for an average zip code. The diamonds show predicted Pick 4 sales per day per adult using the entire regression model from Table 4. This curve and the monthly dummy variables show that 
seasonality has important effects on the sales of the Pick 4 game. Similar to Pick 3, Pick 4 is less popular towards the middle of the year. The curve with squares shows predicted Pick 3 sales with the seasonal effects removed. This curve shows a slightly negative time trend, two small temporary jumps in Pick 4 sales due to the Red Ball promotion in June and July 1999 and April and May 2000, and the large 16.6\% gain in sales due to the midday drawings beginning on August 16, 1999.

\section{Regressions Results with Demographic Interactions Terms}

The previous section estimated the average effect of Ohio Lottery marketing innovations on both Pick 3 and Pick 4 lottery sales per day per adult. There are policy concerns about whether the increase in sales due to midday drawings and the Red Ball promotion is uniform across Ohio or related to certain socioeconomic characteristics. Some policy makers in Ohio have voiced the concern that midday drawings target the disadvantaged, but so far there has been no study of whether sales of the number games increase the most in disadvantaged areas when midday drawings begin.

We estimate the following regression model for Pick 3 sales per day per adult and also for Pick 4 sales per day per adult:

$$
y_{i t}=x_{i t}^{\prime} B+z_{i}^{\prime} \alpha_{i}+e_{i t}
$$

where i indexes zip codes and t indexes months. Building on our previous model, we add interaction terms between the dummy variables for both marketing innovations - midday drawings and Red Ball promotions - and various socioeconomic variables. We create interaction terms of the midday drawing dummy with per capita income, percent black population, percent senior citizen population, percent of the population age 25 or older with at least a college education, and percent of households on public assistance. We 
also control for Super Lotto jackpot size by including the monthly Super Lotto jackpot average (in millions) as an independent variable. Finally, to control for the effect over time of reduced lottery sales due to casino competition, we interact time with distance to casino and time with square of distance to casino.

As before, the model includes a time trend variable ( $t=1$, 2, etc) to control for the slowly declining trend of Pick 3 and Pick 4 sales, and uses monthly dummy variables to control for seasonal influences. The model includes the Red Ball dummy variable, the midday drawing introductory month dummy variable, and the full month midday drawing dummy variable. A constant term is included. Cross-sectional fixed effects control for heterogeneity across zip codes.

Table 5 displays the regression results for Pick 3 sales per day per adult and Pick 4 sales per day per adult. Overall the regression for Pick 3 sales is highly significant, in part due to the cross-section fixed effects, with an F-statistic of 1803.33 and adjusted Rsquared of 0.981 .

The results show that the response of Pick 3 sales to the midday drawing is not uniform across the state, but instead varies with socioeconomic characteristics. All the interaction terms of the full month midday drawing dummy variable with socioeconomic variables are statistically significant. The increase in sales after midday drawings commence is greatest in zip codes with a higher percentage of black residents and areas with a greater percentage of households on public assistance. The increase in sales after the introduction of midday drawings is smaller in zip codes with a higher percentage of residents who are senior citizens and in zip codes with a greater percentage of residents who have at least a college education. 
The coefficient of the midday dummy variable interacted with per capita income is 0.0000008. This means that a $\$ 1,000$ increase in per capita income from the sample mean of $\$ 17,098.95$, results in a $\$ 0.0008$ increase in Pick 3 sales per day per adult after midday drawings are introduced. A ten percentage point increase in the percentage of residents that are black raises Pick 3 sales by $\$ 0.00148$ per day per adult, or $\$ 0.54$ per year per adult after midday drawings are introduced. A ten percentage point increase in the percentage of households who are on public assistance increases Pick 3 sales by \$0.0205 per day per adult, or \$7.48 per year per adult after midday drawings are introduced. A ten percentage point increase in the percentage of residents who are senior citizens decreases Pick 3 sales by $\$ 0.008$ per day per adult, or $\$ 2.91$ per year per adult after midday drawings are introduced. A ten percentage point increase in the percentage of residents that have at least a college education decreases Pick 3 sales by $\$ 0.164$ per day per adult, or \$59.85 per year per adult after midday drawings are introduced.

Discussions with the Ohio Lottery indicate that the Red Ball drawing was introduced in order to create excitement. This extra excitement was not uniform across the state. Only per capita income and the percentage of households on public assistance affect the extra sales during a Red Ball promotion. The coefficient of the Red Ball dummy variable interacted with per capita income is 0.000000416 . This means that a $\$ 1,000$ increase in per capita income from the sample mean of $\$ 17,098.95$ results in a $\$ 0.0042$ increase in Pick 3 sales per day per adult or a \$0.15 increase per year per adult when the Red Ball promotion is in effect. A ten percentage point increase in the percentage of households who are on public assistance increases Pick 3 sales by $\$ 0.0084$ per day per adult, or $\$ 3.08$ per year per adult when the Red Ball promotion is in effect. 
Much of the reduction in Pick 3 sales is due to casino competition. The time trend, the interaction of the time trend with distance to the nearest casino, and the interaction of the time trend with the square of distance to the nearest casino are all statistically significant. While the previous regression model without interaction terms between the time trend and distance to the nearest casino estimates that Pick 3 sales per adult per day fall an average of by $\$ 0.014$ per adult over the 36 months in the sample, this decline is not uniform.

Pick 3 sales decline more over time in zip codes near casinos. This decrease occurs at a decreasing rate as shown in Figure 5. This shows the combined effects of the time trend and the interaction terms of distance and time trend on the change in lottery sales per day per adult over the 36 months in the sample. Within fifteen miles of the nearest casino, Pick 3 sales are estimated to drop by $\$ 0.025$ per day per adult over these thirty-six months. Ninety miles from the nearest casino, Pick 3 sales are estimated to drop by only \$0.01 per day per adult over these thirty-six months. Many of the nearby casinos opened in the mid-1990s and were building their brand recognition and familiarity with gamblers during our sample from 1998 to 2000.

Increases in the Super Lotto jackpot could potentially affect sales of Pick 3 games. However, the coefficient for the Super Lotto jackpot variable was not statistically significantly different from zero. We fail to reject the null hypothesis that these Pick 3 sales are unaffected by the size of the Super Lotto jackpot.

The regression of Pick 4 sales per day per adult shows some similar patterns to the Pick 3 regression. The regression for Pick 4 sales is also highly significant, in part due to 
the cross-section fixed effects, with an F-statistic of 1260.157 and adjusted R-squared of 0.973 .

The increase in sales after midday drawings commence is greatest in zip codes with a higher percentage of black residents, zip codes with a greater percentage of households on public assistance, and zip codes with a higher percentage of residents who are senior citizens. The coefficient of the midday dummy variable interacted with per capita income is 0.00000019 . This means that a $\$ 1,000$ increase in per capita income from the sample mean of $\$ 17,098.95$ results in a $\$ 0.00019$ increase in Pick 4 sales per day per adult, or $\$ 0.07$ per year per adult after midday drawings are introduced. A ten percentage point increase in the percentage of residents that are black raises Pick 4 sales by $\$ 0.00384$ per day per adult, or $\$ 1.40$ per year per adult after midday drawings are introduced. A ten percentage point increase in the percentage of households who are on public assistance increases Pick 4 sales by $\$ 0.00755$ per day per adult, or $\$ 2.76$ per year per adult after midday drawings are introduced. In contrast to our Pick 3 findings, zip codes with a higher percentage of senior citizens spend more on Pick 4 games. A ten percentage point increase in the percentage of senior citizens increases Pick 4 sales by \$0.00291 per day per adult, or \$1.06 per year per adult after midday drawings are introduced. The percentage of residents who have at least a college education has no statistically significant effect on the change in sales after the introduction of midday drawings for the Pick 4 game, unlike the Pick 3 game.

The previous section noted that the excitement generated by the Pick 3 Red Ball promotion had a positive effect on Pick 4 play. We find that this effect was not uniform across the state. However, only the percentage of the population that is black and the 
percentage of households on public assistance affect the extra Pick 4 sales during a Red Ball promotion. The coefficient of the Red Ball dummy variable interacted with percentage black is 0.0000432 . A ten percentage point increase in the percentage of residents who are black is estimated to result in a \$0.0004 increase in Pick 4 sales per day per adult or a $\$ 0.16$ increase per year per adult if the Red Ball promotion is in effect. A ten percentage point increase in the percentage of households who are on public assistance increases Pick 4 sales by $\$ 0.0018$ per day per adult, or $\$ 0.65$ per year per adult when the Red Ball promotion is in effect.

The Pick 4 game is also adversely affected by casino competition. The time trend, the interaction of the time trend with distance to the nearest casino, and the interaction of the time trend with the square of distance to the nearest casino are all statistically significant. While the previous regression model without interaction terms between time and casino proximity estimates that Pick 4 sales per day per adult fall an average of by $\$ 0.00072$ (2.4\%) over the 36 months in the sample, this decline is not uniform.

Pick 4 sales decline more over time in zip codes near casinos. This decrease occurs at a decreasing rate as shown in Figure 6. This figure shows the combined effects of the time trend and the interaction terms between distance and time trend on the change in lottery sales per day per adult over the 36 months in the sample. Pick 4 sales are estimated to drop by $\$ 0.006$ per day per adult over these thirty-six months in zip codes adjacent to a casino. Without any policy innovation by the Ohio Lottery, Pick 4 sales per day per adult would have fallen $20 \%$ over these 36 months in zip codes adjacent to a casino. Pick 4 sales do not have a negative time trend in zip codes farther from casinos. Beyond sixty miles from the nearest casino Pick 4 sales per day per adult would have 
been relatively unchanged over these thirty-six months without any marketing innovation by the Ohio Lottery.

Finally, although increases in the Super Lotto jackpot could potentially affect sales of Pick 4 games, the coefficient for the Super Lotto jackpot variable was not statistically significantly different from zero. We are unable to reject the null hypothesis that Pick 4 sales are unaffected by the size of the Super Lotto jackpot.

\section{Conclusion}

The Ohio Lottery instituted a midday drawing in August 1999 to bolster sales of its struggling Pick 3 and Pick 4 daily numbers games. Pick 3 sales per adult would have declined 15.4\% and Pick 4 sales per adult would have dropped 2.4\% between 1998 and 2000 without any marketing innovations by the Ohio Lottery. This drop in sales was more severe in areas near casinos, many of which opened in the mid 1990s. Midday drawings increased Pick 3 sales 12.1\% per adult and increased Pick 4 sales 16.6\% per adult.

The history of illegal numbers games in Ohio in black neighborhoods in urban areas and a concern that the lottery in general and the numbers games in particular, target disadvantaged groups made midday drawings a controversial innovation. Indeed the increase in both Pick 3 and Pick 4 sales after midday drawings began was greater in zip codes with a greater percentage households receiving public assistance and zip codes with a higher percentage of black residents. Pick 3 and Pick 4 sales increase more in zip codes with higher per capita income after midday drawings began. Pick 3 sales increased less in zip codes with more senior citizens after midday drawings started, while Pick 4 sales increased more in zip codes with more senior citizens after midday drawings began. 
Perhaps there are significant generational differences in preferences for these two lottery products. Pick 3 sales increase less in areas with more college educated residents after midday drawings commence.

The Red Ball promotions were successful in raising Ohio Lottery sales and profits. The Pick 3 Red Ball promotion increased Pick 3 sales per adult by 5.1\% and also increased sales Pick 4 sales 2.2\% per adult. We find that the own-price elasticity of demand for Pick 3 games is -1.24 . The cross-price elasticity of demand between Pick 3 and Pick 4 games is -0.54 . 


\section{References}

Census 2000, U.S. Census Bureau, http://factfinder.census.gov/home/saff/main.html?_lang=en

Clotfelter, Charles T., "On the Regressivity of State-Operated 'Number' Games," National Tax Journal, Vol. 32, 1979.

Clotfelter, Charles T. and Philip J. Cook. 1987. Implicit Taxation in Lottery Finance. National Tax Journal 40 (4):533-46.

Clotfelter, Charles T., and Cook, Philip J. "On the Economies of State Lotteries," Journal of Economic Perspectives, No. 4, Fall 1990: 4.

Cornwell, Christopher and David B. Mustard. The Distributional Impacts of LotteryFunded Aid: Evidence from Georgia's Hope Scholarship. Working Paper. University of Georgia: 2001.

Garrett, Thomas and Thomas L. Marsh. The Revenue Impacts of Cross-Border Lottery Shopping in the Presence of Spatial Autocorrelation. Regional Science and Urban Economics 32 (2002): 501-519.

Hansen, Ann. The Tax Incidence of the Colorado State Lottery Instant Game. Public Finance Quarterly 23, 3 (July, 1995): 385-98.

Hansen, Ann, Anthony D. Miyazaki, and David E. Sprott. The Tax Incidence of Lotteries: Evidence from Five States. The Journal of Consumer Affairs. 34, 2 (Winter, 2000): 182-203.

Oster, Emily. Are All Lotteries Regressive? Evidence from the Powerball. National Tax Journal, 57(2): (June 2004) 79-187.

Price, Donald I., and E. Shawn Novak. The Tax Incidence of Three Texas Lottery Games: Regressivity, Race, and Education National Tax Journal 52, 4 (Dec. 1999): 741751.

Price, Donald I., and E. Shawn Novak. The Income Redistribution Effects of Texas State Lottery Games. Public Finance Review 28, 1 (Jan. 2000): 82-92.

Scott, Frank and John Garen. Probability of Purchase, Amount of Purchase, and the Demographic Incidence of the Lottery Tax. Journal of Public Economics 54, 1 (May, 1994): 57-61.

Siegel, Donald, and Gary Anders. The Impact of Indian Casinos on State Lotteries: A Case Study of Arizona. Public Finance Review 29 (2) (March 2001): 139-147. 
Sourcebook of Zip Code Demographics 1999. CACI Marketing Systems. Fairfax, VA.

Spiro, Michael H. 1974. On the Tax Incidence of the Pennsylvania Lottery. National Tax Journal 27(1):57-61.

Spry, John A. The Determinants of Indiana Lottery Sales. 2003 Proceedings of the National Tax Association. National Tax Association, Chicago, Illinois. November 2003. pp. 198-205.

The Ohio Lottery Commision. Comprehensive Annual Financial Report for Fiscal Years ended June 30, 2006. http://www.ohiolottery.com/pdf/2006_CAFR.pdf

Tosun, Mehmet S. and Mark Skidmore. Interstate Competition and State Lottery Revenues. National Tax Journal 57 (June, 2004): 163-178. 
Table 1: Ohio Lottery Sales 1990 - 2006

\begin{tabular}{|c|c|c|c|c|c|c|c|c|c|c|}
\hline \multirow[b]{2}{*}{$\begin{array}{l}\text { Ohio } \\
\text { Lottery } \\
\text { Product }\end{array}$} & \multirow[b]{2}{*}{ Pick 3} & \multirow[b]{2}{*}{ Pick 4} & \multirow[b]{2}{*}{$\begin{array}{l}\text { Buckeye } \\
\text { 5/Rolling } \\
\text { Cash } 5 \text { (1) }\end{array}$} & \multirow[b]{2}{*}{$\begin{array}{l}\text { Super } \\
\text { Lotto } \\
\text { Plus/Lot' } \\
\text { O Play (2) }\end{array}$} & \multicolumn{2}{|c|}{ (in millions) } & \multirow[b]{2}{*}{ Cards } & \multirow[b]{2}{*}{$\begin{array}{l}\text { Total } \\
\text { Online } \\
\text { Games }\end{array}$} & \multirow[b]{2}{*}{$\begin{array}{l}\text { Instant } \\
\text { Games }\end{array}$} & \multirow[b]{2}{*}{$\begin{array}{l}\text { Total } \\
\text { Lottery } \\
\text { Sales }\end{array}$} \\
\hline & & & & & Kicker & $\begin{array}{l}\text { Mega } \\
\text { Millions }\end{array}$ & & & & \\
\hline 1990 & 414.2 & 77.4 & & 530.8 & 84.6 & & & 1107 & 513.9 & 1620.9 \\
\hline 1991 & 411.7 & 79.1 & & 451.4 & 71.3 & & 24.7 & 1038.2 & 526.3 & 1664.2 \\
\hline 1992 & 411.1 & 85.4 & 25.7 & 500 & 69.5 & & 9.5 & 1101.2 & 584.2 & 1685.4 \\
\hline 1993 & 428.3 & 91 & 122.4 & 493.5 & 65.6 & & & 1200.8 & 775.7 & 2117.2 \\
\hline 1994 & 421 & 91.9 & 118.2 & 370.6 & 54.3 & & & 1149.7 & 1032.6 & 2182.3 \\
\hline 1995 & 446.2 & 102.1 & 100.3 & 437.8 & 63.3 & & & 1149.7 & 1032.6 & 2182.3 \\
\hline 1996 & 450.6 & 108.2 & 87.3 & 455.8 & 66.7 & & & 1168.6 & 1146.1 & 2314.7 \\
\hline 1997 & 435.6 & 116.5 & 78.8 & 410.6 & 63.5 & & & 1105 & 1195 & 2300 \\
\hline 1998 & 421.1 & 124 & 73.8 & 384.9 & 60.5 & & & 1064 & 1131.8 & 2195.8 \\
\hline 1999 & 399.4 & 125.1 & 69.9 & 364.4 & 57.2 & & & 1016 & 1128.7 & 2144.7 \\
\hline 2000 & 427.3 & 144.6 & 62.2 & 336.6 & 52.9 & & & 1023.6 & 1126.8 & 2150.4 \\
\hline 2001 & 419 & 150.7 & 56.5 & 262.5 & 42.9 & & & 931.6 & 988.3 & 1919.9 \\
\hline 2002 & 409.2 & 154.6 & 62.4 & 297.9 & 45 & 16.5 & & 985.6 & 997.5 & 1983.1 \\
\hline 2003 & 401.8 & 154.2 & 68.9 & 160.7 & 27.3 & 176.2 & & 989.1 & 1089.1 & 2078.3 \\
\hline 2004 & 396.8 & 165.2 & 66.6 & 143.8 & 24.5 & 191.8 & & 988.7 & 1166 & 2154.7 \\
\hline 2005 & 387.7 & 170.1 & 74.8 & 113 & 19.9 & 176.4 & & 941.9 & 1217.2 & 2159.1 \\
\hline 2006 & 377.3 & 175.7 & 72.6 & 76.3 & 21.6 & 223.4 & & 946.9 & 1274 & 2220.9 \\
\hline
\end{tabular}

Source: The Ohio Lottery Commission. Comprehensive Annual Financial Report for Fiscal Years ended June 30, 2006 and 2005. http://www.ohiolottery.com/pdf/2006_CAFR.pdf 
Table 2: Pick 3 and Pick 4 Sales as a \% of Total Lottery Sales, 1990-2006

\begin{tabular}{|c|c|c|}
\hline $\begin{array}{l}\text { Fiscal } \\
\text { Year }\end{array}$ & $\begin{array}{l}\text { Pick } 3 \text { Sales as } \\
\text { a \% of Total } \\
\text { Lottery Sales }\end{array}$ & $\begin{array}{l}\text { Pick } 4 \text { Sales as } \\
\text { a \% of Total } \\
\text { Lottery Sales }\end{array}$ \\
\hline 1990 & $25.60 \%$ & $4.80 \%$ \\
\hline 1991 & $24.70 \%$ & $4.80 \%$ \\
\hline 1992 & $24.40 \%$ & $5.10 \%$ \\
\hline 1993 & $20.20 \%$ & $4.30 \%$ \\
\hline 1994 & $19.30 \%$ & $4.20 \%$ \\
\hline 1995 & $20.40 \%$ & $4.70 \%$ \\
\hline 1996 & $19.50 \%$ & $4.70 \%$ \\
\hline 1997 & $18.90 \%$ & $5.10 \%$ \\
\hline 1998 & $19.20 \%$ & $5.60 \%$ \\
\hline 1999 & $18.60 \%$ & $5.80 \%$ \\
\hline 2000 & $19.90 \%$ & $6.70 \%$ \\
\hline 2001 & $21.80 \%$ & $7.80 \%$ \\
\hline 2002 & $20.60 \%$ & $7.80 \%$ \\
\hline 2003 & $19.30 \%$ & $7.40 \%$ \\
\hline 2004 & $18.40 \%$ & $7.70 \%$ \\
\hline 2005 & $18.00 \%$ & $7.90 \%$ \\
\hline 2006 & $17.00 \%$ & $7.90 \%$ \\
\hline
\end{tabular}

Source: The Ohio Lottery Commission. Comprehensive Annual Financial Report for Fiscal Years ended June 30, 2006 and 2005. http://www.ohiolottery.com/pdf/2006_CAFR.pdf 


\section{Table 3: Descriptive Statistics}

\section{Variable}

Pick3 sales per day per adult (\$)

Pick4 sales per day per adult (\$)

Per capita income (\$)

Percent black population

Percent senior population (65-99)

Percent on public assistance

Percentage college graduates or greater

education

Mileage to nearest casino

Square of mileage to nearest casino

SuperLotto jackpot monthly average (\$mill.)

Red Ball promotion dummy

Midday drawing dummy

$\begin{array}{rrrr}\text { Mean } & \begin{array}{c}\text { Standard } \\ \text { Deviation }\end{array} & \text { Minimum } & \text { Maximum } \\ 0.09 & 0.16 & 0 & 2.61 \\ 0.03 & 0.05 & 0 & 0.80 \\ 17098.95 & 5613.86 & 0 & 70737.00 \\ 6.96 & 17.08 & 0 & 98.30 \\ 11.58 & 3.17 & 0 & 29.60 \\ 2.94 & 3.13 & 0 & 31.96 \\ & & & \\ 15.90 & 12.09 & 0 & 90.62 \\ 67.4 & 29.2 & 2.22 & 127.2 \\ 5388.7 & 3984.0 & 4.93 & 16167.1 \\ 11.65 & 3.93 & 6.11 & 26.33 \\ 0.11 & 0.31 & 0.00 & 1.00 \\ 0.42 & 0.49 & 0.00 & 1.00\end{array}$


Table 4: Regression Results for Pick 3 and Pick 4 Sales per day per adult

Constant

February

March

April

May

June

July

August

September

October

November

December

Time Trend

Red Ball Dummy Variable

Midday Introductory Month

Dummy Variable

Midday Full Month Dummy

Variable

Cross Section Fixed Effects

Period Fixed Effects

Pick 3 per day per adult

coefficient

$0.09535 \quad 204.60$

Pick 4 per day per adult

coefficient

0.02866

t-stat

0.00096

1.61

0.00220

3.70

0.00114

1.86

$-0.00041$

$-0.67$

$-0.00188$

$-3.04$

$-0.00496$

$-7.97$

$-0.00546$

$-8.12$

$-0.00580$

$-9.65$

$-0.00585$

$-9.69$

$-0.00474$

$-7.79$

$-0.00362$

$-5.90$

$-0.00039$

$-14.82$

0.00458

9.85

0.00808

8.70

$-0.00033$

150.89

$-0.00012$

$-1.36$

$-0.00015$

$-0.49$

$-0.00037$

$-0.58$

$-0.00097$

$-1.47$

$-0.00165$

$-3.85$

$-0.00166$

$-6.52$

$-0.00188$

$-6.07$

$-0.00118$

$-7.67$

$-0.00088$

$-4.79$

$-0.00064$

$-3.53$

$-0.00002$

$-2.57$

0.00066

$-2.29$

R-squared

Adjusted R-squared

S.E. of regression

F-statistic

Prob (F-statistic)

Durbin-Watson

Mean of dependent variable

$0.01095 \quad 20.19$

0.00227

5.99

0.01095

yes

no

0.981

0.980

0.023

1776.068

0.000

0.324

0.091

$0.00498 \quad 22.51$

0.164

yes

no

0.968

0.967

0.009

1027.580

0.000

0.307

0.030

0.051

S.D. of dependent variable 
Table 5: Regressions Results with Demographic Interactions Terms

Constant

February dummy

March dummy

April dummy

May dummy

June dummy

July dummy

August dummy

September dummy

October dummy

November dummy

December dummy

Time Trend

Red Ball dummy

Midday Full Month Dummy Variable

Midday dummy * per capita income

Midday dummy * \% black population

Midday dummy * \% senior population

Midday dummy * \% on public assistance

Midday dummy $* \%$ college grads or greater

Midday Introductory Month Dummy Variable

Midday introduction month dummy * per capita

income

Midday introduction month dummy * \% black

population

Midday introduction month dummy * \% senior

population

Midday introduction month dummy * \% on

public assistance

Midday introduction month dummy * \% college

grads or greater

Red Ball dummy * per capita income

Red Ball dummy * \% black population

Red Ball dummy * \% senior population

Red Ball dummy * \% on public assistance

Red Ball dummy * \% college grads or grea

Time*Mileage to nearest casino

Time*Square of mileage to nearest casino

SuperLotto jackpot monthly average

Cross Section Fixed Effects

Period Fixed Effects

R-squared

Adjusted R-squared

S.E. of regression

F-statistic

Prob(F-statistic)

Durbin-Watson

Mean of dependent variable

Pick 3 per day per adult |Pick 4 per day per adult

coefficient

0.0951690

t-stat

coefficient

0.0009250

146.68

0.0022350

1.58

0.0010970

3.80

$-0.0003570$

1.81

$-0.58$

$-0.0019660$

$-3.15$

$-0.0049570$

$-8.08$

$-0.0055570$

$-8.18$

$-0.0058030$

$-9.80$

$-0.0058780$

$-9.87$

$-0.0047440$

$-7.92$

$-0.0037270$

$-5.92$

$-0.0007910$

$-13.62$

$-0.0023450$

$-1.09$

0.0020890

1.45

0.0000008

10.43

0.0001480

7.46

$-0.0007960$

$-9.89$

0.0020500

17.65

$-0.0163980$

$-4.83$

0.0115330

2.78

0.0000004

1.87

0.02896900

t-stat

$-0.00029600$

120.05

$-0.00014800$

$-1.36$

$-0.00010000$

$-0.68$

$-0.00042400$

$-0.44$

$-0.00088500$

$-1.86$

$-0.00166200$

$-3.81$

$-0.00157100$

$-7.29$

$-0.00188100$

$-6.22$

$-0.00116000$

$-8.54$

$-0.00087300$

$-5.24$

$-0.00053400$

$-3.92$

$-0.00016500$

$-2.28$

$-0.00078800$

$-7.65$

$-0.00632600$

$-0.99$

0.00000019

$-11.77$

0.00038400

6.76

0.00029100

52.24

0.00075500

9.73

$-0.00116200$

17.48

0.00025100

$-0.92$

0.0000004

0.00000007

0.16

$-0.0000954$

$-1.60$

$-0.0009370$

$-3.91$

0.0008590

2.45

$-0.0104100$

$-1.02$

0.0000004

3.51

0.0000425

1.38

$-0.0001360$

$-1.10$

0.0008430

4.65

$-0.0091640$

$-1.74$

0.0000083

4.96

0.0000000

$-2.40$

0.0000228

0.61

0.00013500

0.76

$-0.00004550$

6.08

0.00018400

$-0.51$

$-0.00104400$

0.00000007

$-0.28$

0.00004320

1.57

$-0.00003680$

3.75

0.00017900

$-0.80$

$-0.00038600$

2.65

0.00000331

$-0.20$

$-0.00000002$

5.29

$-0.00002290$

$-3.50$

yes

no

0.982

0.981

0.023

1803.33

0.000

0.337

0.091

0.164

$-1.65$

S.D. of dependent variable

$\begin{array}{rr}\text { yes } & -1.65 \\ \text { no } & \\ 0.974 & \\ 0.973 & \\ 0.008 & \\ 260.157 & \\ 0.000 \\ 0.382 \\ 0.030 \\ 0.051\end{array}$


Figure 1: Pick 3 and Pick 4 Yearly Sales, 1990 - 2006

Ohio Lottery Pick 3 and Pick 4 Sales

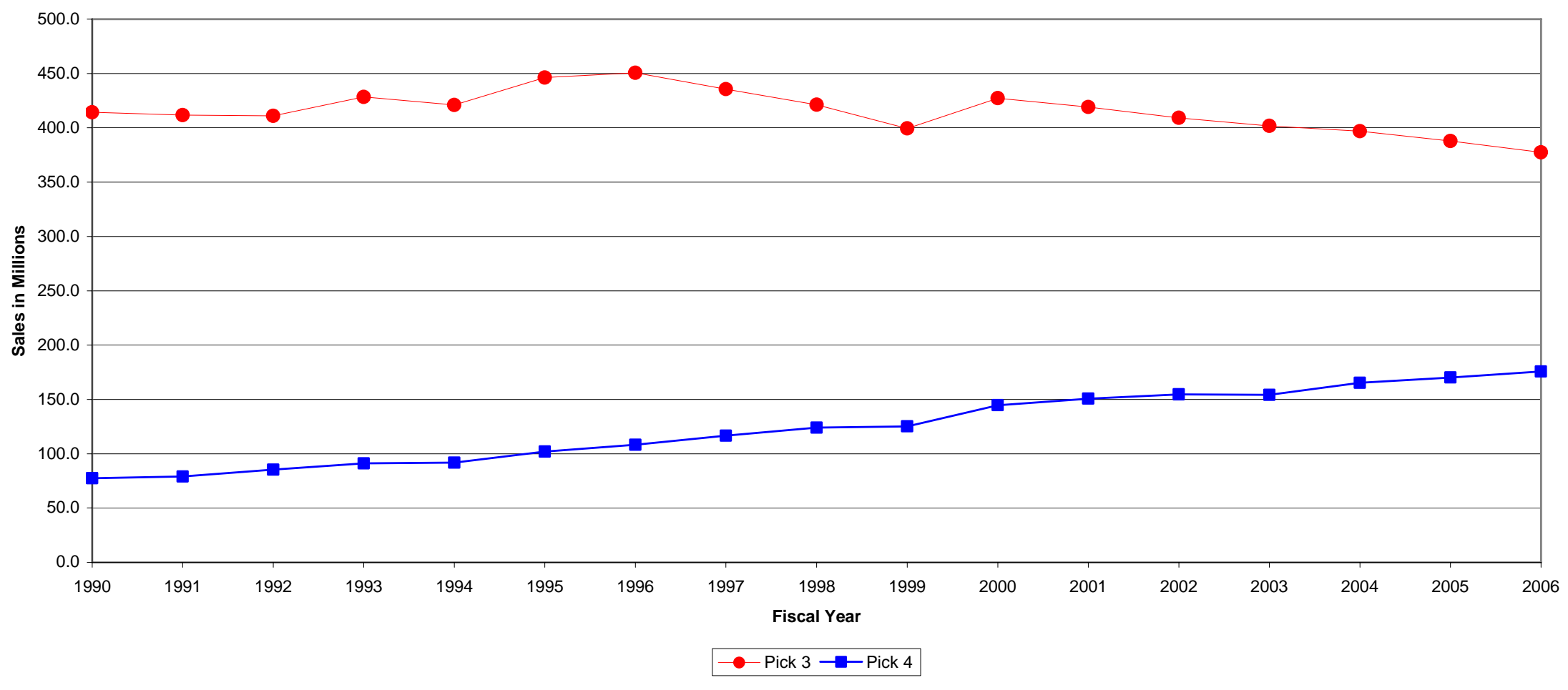


Figure 2:

Pick 3 sales per day per adult and Pick 4 sales per day per adult Monthly data Jan 98 - Dec 00

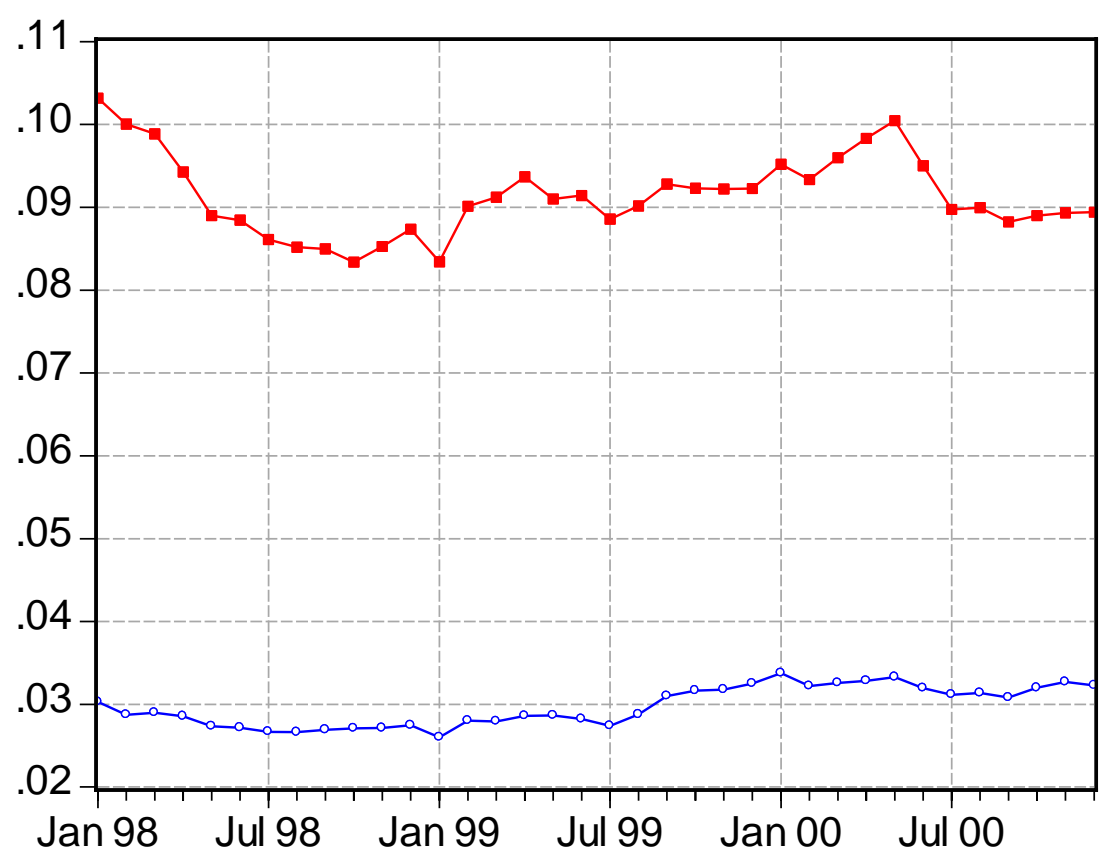

mean PICK 4 sales per day per adult (\$) mean PICK 3 sales per day per adult (\$) 
Figure 3: Predicted Pick 3 Sales Per Day Per Adult for an Average Zip Code 1998-2000

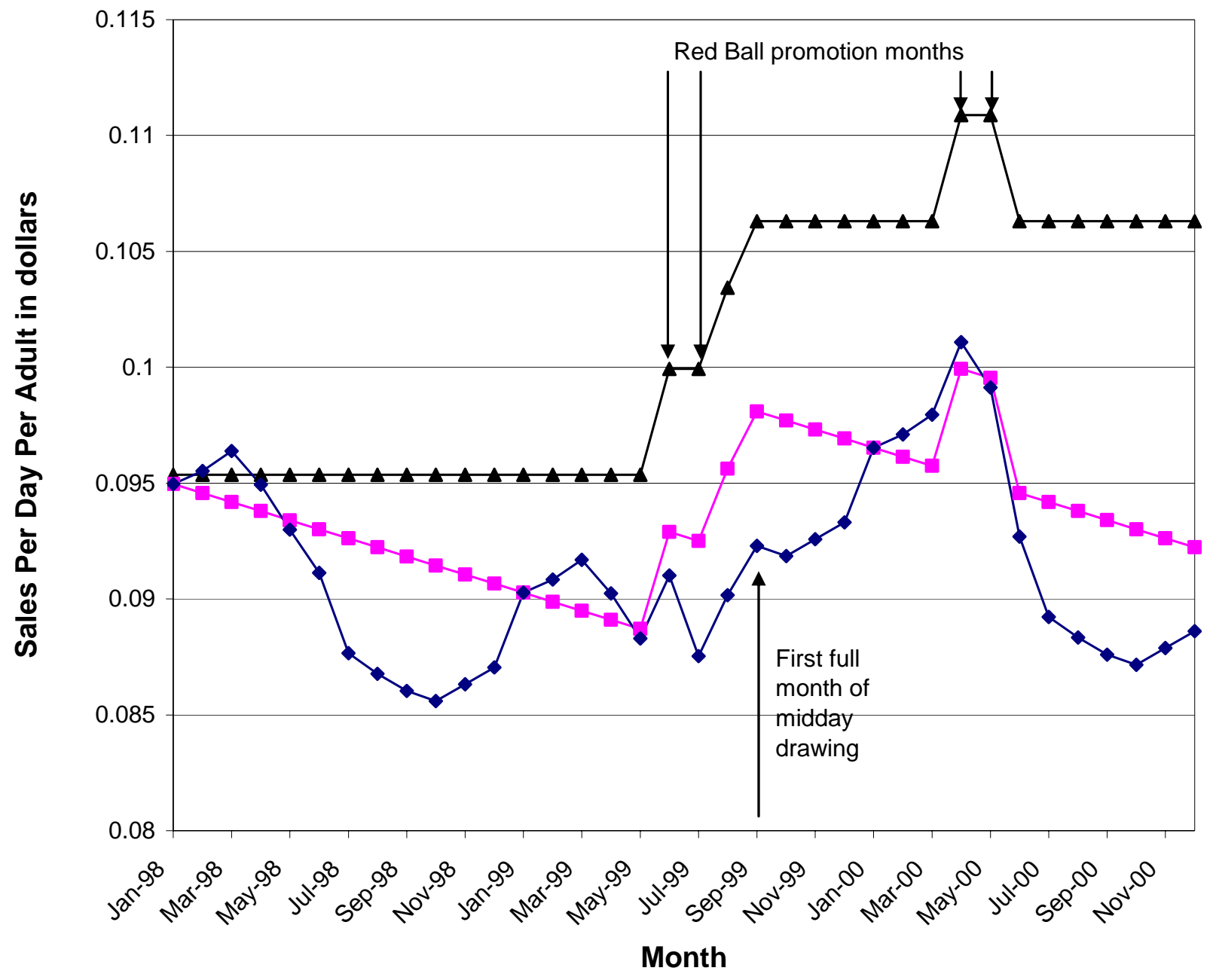

\-Predicted Sales with seaonality and time trend removed

$\rightarrow$ - Predicted Sales with seasonalilty removed

$\longrightarrow$ Predicted Sales full model

Month 
Figure 4: Predicted Pick 4 Sales Per Day Per Adult for an Average Zip Code 1998 - 2000

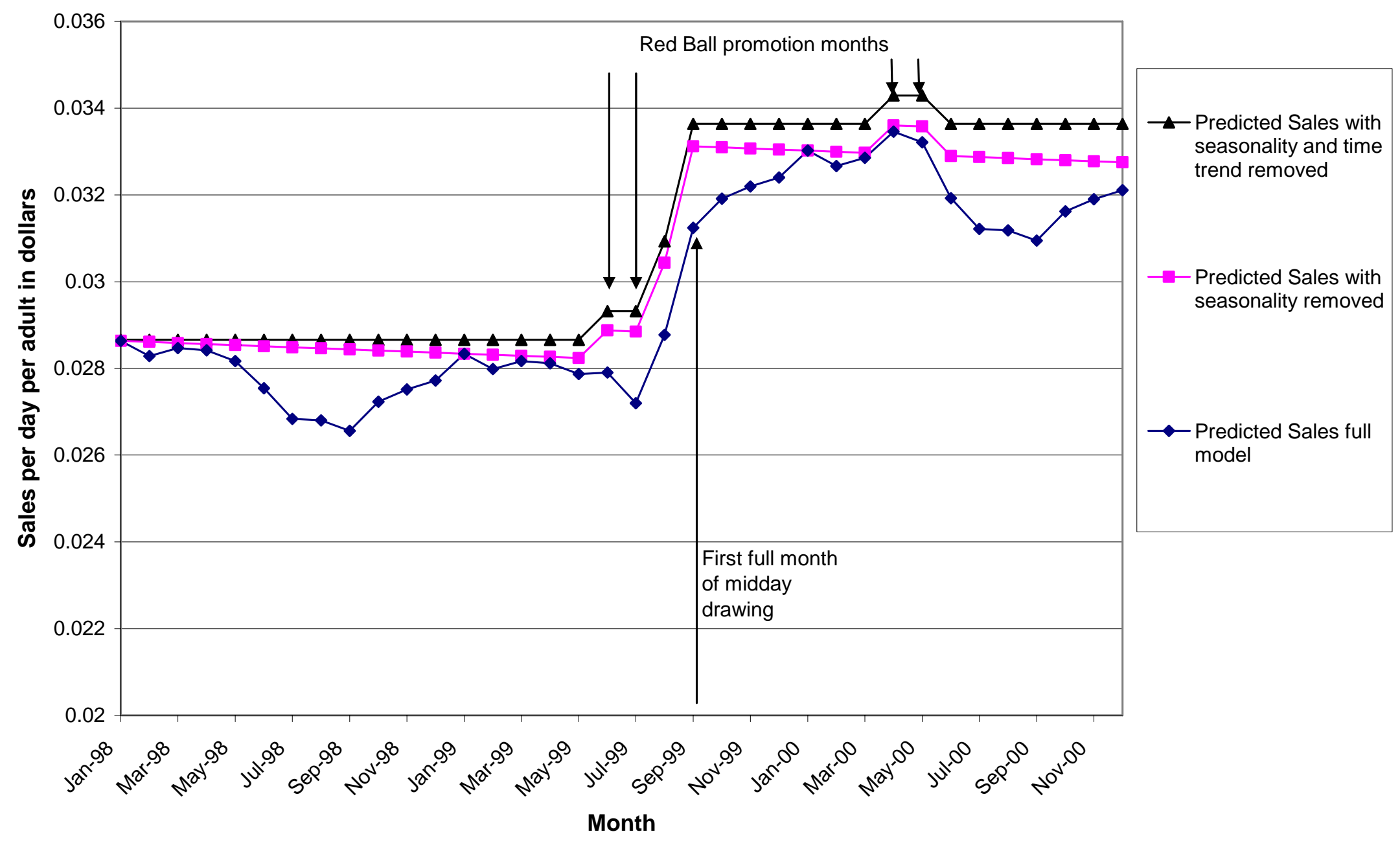


Figure 5: Change in Pick 3 Sales Per Day Per Adult vs. Distance to Nearest Casino

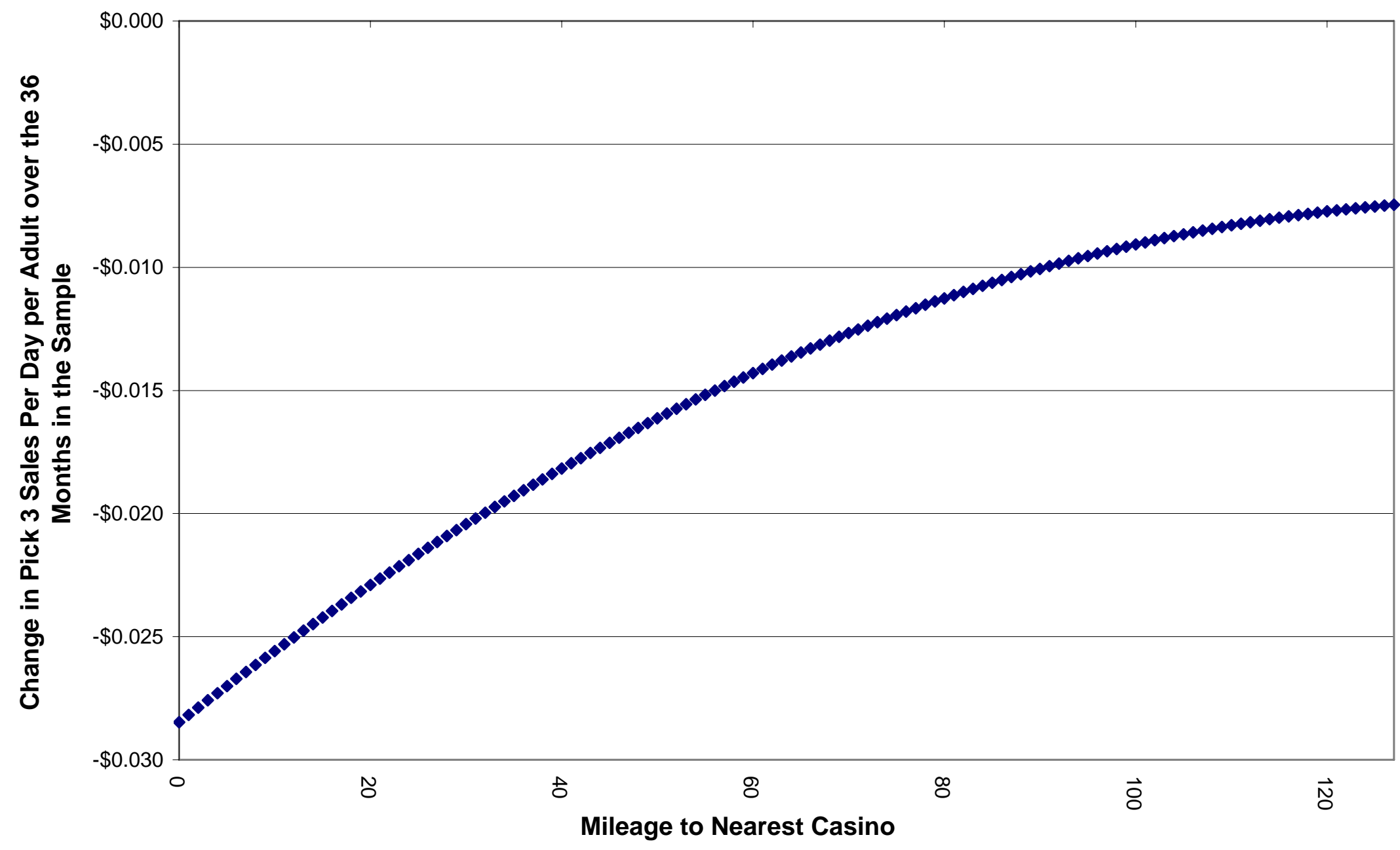


Figure 6: Change in Pick 4 Sales Per Day Per Adult vs. Distance to Nearest Casino

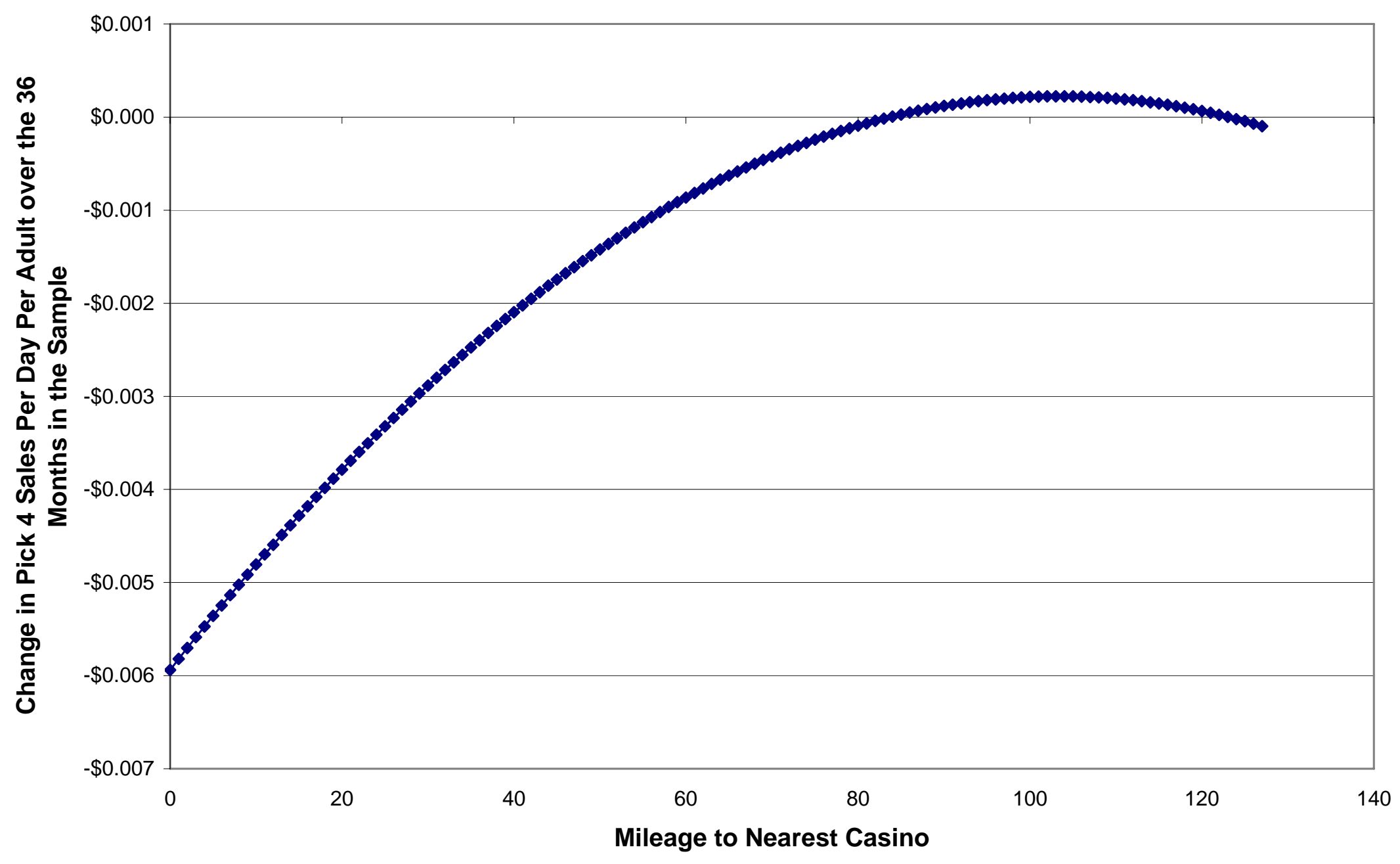

